Check for updates

Edinburgh, UK

Cite this as: BMJ 2020;371:m4225 http://dx.doi.org/10.1136/bmi.m4225 Published: 29 October 2020

\title{
Covid-19: 338 patients with the virus were discharged from Scottish hospitals to care homes
}

\section{Bryan Christie}

A total of 338 patients with a diagnosis of covid-19 were discharged from Scottish hospitals into care homes in the three months from March this year, says a report from Public Health Scotland. ${ }^{1}$

The discharges were necessary to free up space in hospitals for covid-19 patients but some care home owners have claimed that it introduced the virus into their premises, causing almost 2000 deaths across Scotland. ${ }^{2}$

Public Health Scotland says that most of the 3599 discharges that took place in the busiest month of March were among people who had never been tested. Of the 650 who were tested, 78 were positive, but the discharges still went ahead.

The Scottish government introduced guidance on 21 April that meant people being discharged into care homes required two negative tests. Following that change, $93 \%$ of people were tested but the report says 45 patients were still transferred to care homes despite not having two negative tests.

Public Health Scotland has analysed data around discharges and concluded that 338 patients had a diagnosis of covid-19 on their discharge record before being moved to a care home. Not all these cases were confirmed by a laboratory test and may include suspected cases.

Scotland has been found to have the highest rate of covid-19 related deaths in care homes of any part of the UK. A report published in August found that $47 \%$ of overall deaths linked to the virus occurred in care homes compared with $42 \%$ in Northern Ireland, 30\% in England, and 28\% in Wales. ${ }^{3}$ The Public Health Scotland report records a total of 1915 covid-19 related deaths in care homes in the three months from March.

Just under a third of Scottish care homes had a covid-19 outbreak and larger care homes were more likely to be affected. Outbreaks affected $90 \%$ of homes with more than 90 residents compared with just under $4 \%$ of those with fewer than 20 residents.

The report said that hospital discharge is associated with an increased risk of an outbreak when considered on its own, but added, "After accounting for care home size and other characteristics, the estimated risk of an outbreak reduces and is not statistically significant.”

Donald Macaskill, the chief officer of Scottish Care which represents care home providers, said the statistical analysis is only part of the story. "What is missing among all the numbers and charts is the story of those who cared for residents. Some of our members and staff believe that covid-19 was introduced into their care home community as a result of discharges. I hope the researchers can take some time to listen to staff in care homes where there have been significant outbreaks.”

The Scottish health secretary Jeane Freeman said, "The data from this report gives us a better understanding of the impact of discharges on outbreaks in care homes. We will continue to adapt our guidance and the steps we are taking to protect care home staff and residents in line with the latest data, scientific evidence, and clinical advice."

1 Public Health Scotland. Discharges from NHS Scotland Hospitals to Care Homes between 1 March and 31 May 2020. October 2020.

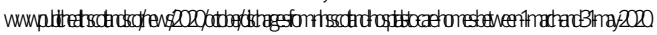

2 Public Health Scotland. Discharges from NHS Scotland hospitals to care homes. Between 1 March and 31 May 2020. A Management Information Statistics publication for Scotland https://beta.isdscotland.org/find-publications-and-data/population-health/covid-19/discharges-from-nhsscotlandhospitals-to-care-homes.

3 International Long Term Care Policy Network. Covid-19 mortality and long-term care: a UK comparison. August 2020. https://tccovid.org/wpcontent/uploads/2020/08/COVID-19-mortality-in-long-term-care-final-Sat29-v1.pdf. 